\title{
Perioperative Care of a Patient With Waardenburg Syndrome
}

\author{
Miranda Holbrook ${ }^{\mathrm{a}, \mathrm{c}}$, Joseph D. Tobias ${ }^{\mathrm{b}}$
}

\begin{abstract}
Waardenburg syndrome is a genetic disorder, resulting in defective control of the division and migration of neural crest cells including the melanocyte lineage during embryonic development. Primary involvement of melanocytes results in the characteristic phenotypic involvement including a white forelock, vitiligo, and heterochromia. Involvement of the organ of Corti leads to sensorineural hearing loss. Involvement of the craniofacial mesenchyme results in abnormal facial features, airway abnormality, and upper limb involvement malformations. Given the potential for end-organ involvement, surgical intervention may be required. Specific concerns during anesthetic care include the potential for difficulties with endotracheal intubation, tracheal involvement, impairment of communication related to deafness, and associated congenital heart disease.
\end{abstract}

Keywords: Waardenburg syndrome; Anesthesia; Airway; Sensorineural hearing loss

\section{Introduction}

Waardenburg syndrome is a genetic disorder whose primary phenotypic features include a white forelock, vibrant blue eyes or heterochromia due to lack of pigmentation of the iris, distinctive facial abnormalities (laterally displaced inner canthi and a wide nasal bridge), sensorineural hearing loss, and upper extremity malformations [1]. The embryological progenitor cells (neural crest cells) that result in the formation of pigment-forming melanocytes and the body's connective tissue framework are affected. Anesthetic care may be required

Manuscript submitted July 15, 2021, accepted July 29, 2021

Published online September 29, 2021

${ }^{a}$ Heritage College of Osteopathic Medicine - Dublin Campus, Ohio University, Athens, $\mathrm{OH}$, USA

bDepartment of Anesthesiology \& Pain Medicine, Nationwide Children's Hospital and the Department of Anesthesiology \& Pain Medicine, The Ohio State University College of Medicine, Columbus, OH, USA

${ }^{\mathrm{c} C}$ Corresponding Author: Miranda Holbrook, Heritage College of Osteopathic Medicine - Dublin Campus, Ohio University, Athens, OH, USA.

Email:mh801719@ohio.edu

doi: https://doi.org/10.14740/jmc3751 during various surgical procedures aimed at treating the endorgan involvement of the disease process. We report a 6-yearold boy with Waardenburg syndrome who required anesthetic care during dental surgery. The perioperative concerns of these patients are discussed, previous reports of anesthetic care reviewed, and options for anesthetic care presented.

\section{Case Report}

\section{Investigations}

Review of this case and presentation in this format followed the guidelines of the Institutional Review Board of Nationwide Children's Hospital (Columbus, $\mathrm{OH}$ ).

The patient was a 6-year-old boy who presented for anesthetic care during dental rehabilitation. Past medical history of the child included an uncomplicated pregnancy and delivery at 40 weeks gestation. The child passed his newborn hearing test and was meeting appropriate developmental milestone. Other past medical and surgical history was negative.

\section{Diagnosis}

Given a family history of Waardenburg syndrome and characteristic phenotypic findings (heterochromia of the iris with inner canthi displacement and a wide, flat nasal bridge), a diagnosis of type I Waardenburg syndrome was made at 8 months of age.

\section{Treatment}

The child presented for dental rehabilitation and treatment of multiple dental carries under general anesthesia. Physical examination revealed a child in no acute distress. He was normocephalic with wide-set eyes, flat nasal bridge hypertelorism and a wide flat nasal bridge. Airway examination revealed a Mallampati class I with a thyromental distance of 3 fingerbreadths. Mouth opening and neck range of motion were within normal limits. The cardiac and respiratory examinations were normal. The patient was held nil per os for $6 \mathrm{~h}$ and transported to the operating room. Routine American Society of Anesthesiologists' monitors were placed. Following the inhalation induction of anesthesia with sevoflurane in nitrous oxide and oxygen, a pe- 
ripheral intravenous cannula was placed. Bag-valve-mask ventilation was easy. Propofol $(2.5 \mathrm{mg} / \mathrm{kg})$ was administered and following direct laryngoscopy, his trachea was intubated with a $5.5 \mathrm{~mm}$ cuffed endotracheal tube. The surgical time was 60 min. Total fluids included $400 \mathrm{~mL}$ of lactated Ringer's. Postoperative analgesia was provided by ketorolac $(0.5 \mathrm{mg} / \mathrm{kg})$ and morphine $(2 \mathrm{mg})$. Prophylaxis for the prevention of postoperative nausea and vomiting was provided by ondansetron $(3 \mathrm{mg})$ and dexamethasone $(4 \mathrm{mg})$. At the completion of the surgical procedure, his trachea was extubated and he was transferred to the post-anesthesia care unit.

\section{Follow-up and outcomes}

The remainder of his postoperative course was unremarkable and he was discharged home the same day.

\section{Discussion}

Waardenburg syndrome, a disorder of the neural crest cells, was first observed in deaf mute twin girls by the Dutch ophthalmologist, Jan van der Hoeve in 1916. However, it was not until 1951 that the ophthalmologist and geneticist, Dr. Petrus Johannes Waardenburg, fully defined the characteristics of the syndrome, which bears his name $[2,3]$. Waardenburg syndrome affects the differentiation and migration of neural crest cells, specifically the melanocyte-forming lineage. Involvement of melanocytes leads to a lack of pigmentation including the characteristic white forelock in the hair, heterochromia of the iris or vibrant blue eyes, as well as hypopigmented patches of the skin and vitiligo. In the inner ear, the lack of melanocytes and malformation or absence of the organ of Corti leads to sensorineural hearing loss [1]. Involvement of cephalic neural crest cells that form the craniofacial mesenchyme results in abnormal facial features and upper limb involvement, specific for Waardenburg syndrome type III.

Divided into four subclasses, the classifications of Waardenburg syndrome distinguish between the varied phenotypic presentations dependent upon the location and severity of gene mutation. Type 1 primarily involves the face and pigmentation alterations of the hair, skin, and eyes with a smaller proportion having sensorineural hearing loss. Type 2 has a higher prevalence of hearing loss, but lacks the presenting dystopia canithorum found in type 1 Waardenburg syndrome patients. A small subset, called type 3 Waardenburg syndrome or KleinWaardenburg, has additional musculoskeletal malformations, particularly in the upper limbs with flexion contractures, fusion of carpal bones, and/or syndactyly [3, 4]. Type 4 is often called Shah-Waardenburg syndrome. These individuals exhibit the classic phenotypic findings of Waardenburg syndrome in association with Hirschsprung disease, related to deficient neural crest cell development of the myenteric plexus in the colon. Type IV lends further support for the primary defect involving neural crest cells given the association of Waardenburg syndrome and Hirschsprung disease [2, 5]. In addition to the varied phenotypic expression, inheritance also varies from autosomal dominant or recessive.

Waardenburg syndrome is the result of mutations in one of several genes that control the division and migration of neural crest cells during embryonic development [6]. Neural crest cells are multipotent progenitor cells arising from the embryological ectodermal layer. As the cells migrate throughout the body, they give rise to neurons, neuroglia, craniofacial, skeletal, connective tissues, and melanocytes. Autosomal dominant inheritance is involved in mutations of the PAX3 (2q35), MITF (3p14.1-p12.3), SOX10, EDNRB, or EDNR3 genes [7, 8]. The MITF (microphthalmia-associated transcription factor) gene functions in a critical stage of melanogenesis by stimulating the differentiation of melanocytes through the activation of a tyrosinase enzyme. PAX3, the most common mutation in Waardenburg syndrome, and SOX10 both operate as MITF regulators by binding to the MITF's proximal site, thus also impacting melanogenesis in affected individuals $[7,9]$. Mutations of the EDNRB and EDNR3 genes result in a deficiency in a growth promoting pathway, the endothelin-signaling pathway, of neural crest cells. As this pathway functions to enhance the proliferation of neural crest cells in the pluripotent stage of development, specific effects are seen in melanocytes and enteric nervous system development due to the abundance of cells needed and the long migration distance from the neural crest cells original embryologic site of development [10]. The EDNRB and EDNR3 mutations explain the association of the phenotypic expression of Waardenburg syndrome and a lack of colonic ganglion migration seen in Hirschsprung disease.

As with other chromosomal and genetic abnormalities, Waardenburg syndrome results in a specific pattern of endorgan involvement and anatomical malformations which may require surgical intervention. Although the disease has an incidence of 1 in 40,000, there remains limited information regarding anesthetic care for these patients $[2,5,6,11-18]$. As with all intraoperative care, the anesthetic approach begins with a thorough preoperative evaluation and identification of the endorgan involvement. The limited literature regarding anesthetic care in these patients has anecdotally suggested the potential for difficulties with airway management and endotracheal intubation [11]. Michalek et al described a 46-year-old patient with Waardenburg syndrome who presented for dental rehabilitation. Preoperative examination was limited due to a lack of patient cooperativity, but did demonstrate a short thyromental distance, and limited neck mobility. As direct laryngoscopy and endotracheal intubation was not feasible due to limited mouth opening and neck movement, a supraglottic airway was placed and endotracheal intubation was performed through the airway using fiberoptic guidance. The authors concluded that although anesthesia-related information regarding anesthesia and airway management in Waardenburg syndrome is limited, specific facial features and muscle contractures may cause difficulties with both direct laryngoscopy and endotracheal intubation. In our patient preoperative airway examination revealed Mallampati class I with a thyromental distance of 3 fingerbreadths. Mouth opening and neck range of motion were within normal limits. Given the potential for airway involvement with Waardenburg syndrome, the ability to accomplish adequate bag-valve mask ventilation should be demonstrated prior to the use of neuromuscular blocking agents. The appro- 
Table 1. End-Organ Involvement and Anesthetic Implications of Waardenburg Syndrome

\begin{tabular}{|c|c|c|}
\hline Disease & Organ involvement & Anesthetic implications \\
\hline \multirow[t]{2}{*}{ Waardenburg type 1} & $\begin{array}{l}\text { Difficult airway and tracheal involvement: } \\
\text { congenital abnormalities of the glottis, larynx, } \\
\text { and trachea; airway involvement with muscle } \\
\text { contractures, facial structure anomalies }\end{array}$ & $\begin{array}{l}\text { Preoperative airway evaluation. Consultation } \\
\text { with pediatric otorhinolaryngology specialist. } \\
\text { Equipment for difficult airway management. }\end{array}$ \\
\hline & $\begin{array}{l}\text { Cardiac involvement: associated } \\
\text { congenital cardiac disease }\end{array}$ & Preoperative cardiac evaluation and echocardiogram \\
\hline \multirow[t]{3}{*}{ Waardenburg type 2} & Difficult airway and tracheal involvement & \\
\hline & Cardiac involvement & \\
\hline & Sensorineural deafness & \\
\hline Waardenburg type 3 & Difficult airway and tracheal involvement & \\
\hline \multirow[t]{4}{*}{ Waardenburg type 4} & Difficult airway and tracheal involvement & \\
\hline & Cardiac involvement & \\
\hline & Sensorineural deafness & \\
\hline & Hirschsprung disease & $\begin{array}{l}\text { Preoperative, intraoperative, postoperative electrolyte monitoring. } \\
\text { Assess for concerns associated with malnutrition and constipation. }\end{array}$ \\
\hline
\end{tabular}

priate equipment for dealing with a difficult airway should be readily available including equipment for indirect laryngoscopy [19].

In addition to the potential for difficulties with endotracheal intubation, congenital abnormalities of the glottis, larynx, and trachea have been reported including laryngomalacia and subglottic narrowing $[6,20]$. The lineage of both melanocytes and laryngeal cartilage can be traced back to the neural crest cells explaining this association. Thapa et al reported an omega-shaped, floppy epiglottis with redundant aryepiglottic folds, and exaggerated arytenoids in a 45-day-old infant with Waardenburg syndrome [20]. An additional report outlined normal direct laryngoscopy, but difficulties passing an appropriate sized endotracheal tube $(4.5 \mathrm{~mm})$ due to sub-glottic resistance in a 4-year-old child [6]. The trachea was eventually intubated with a $3.0 \mathrm{~mm}$ uncuffed endotracheal tube and the case proceeded uneventfully. Given these concerns, preoperative consultation with otolaryngology may be indicated based on the patient's preoperative history and physical examination.

Embryologic research of the PAX3 gene, which is mutated in type 1 Waardenburg syndrome, has demonstrated its involvement in the septation of the primitive heart in mice, leading to a possible connection between congenital heart defects and Waardenburg syndrome including atrial septal defects and persistence of embryologic structures (persistent left superior vena cava) [21-24]. Another report outlines the association of dilated cardiomyopathy in a Waardenburg syndrome patient; however, the authors did not provide a specific causal relation- ship, but rather speculated that it may have been an unrelated association [25]. Given these potential associations, preoperative echocardiogram is suggested if the history or physical examination suggests associated cardiac involvement.

Additional somatic involvement of Waardenburg syndrome includes muscular hypoplasia of the upper extremities, flexion contractures in the wrist and hands, fused carpal bones, and syndactyl. These concerns may affect intraoperative positioning, placement of monitoring devices, and vascular access [4]. Sensorineural hearing loss may impact perioperative communication. The use of speech amplification devices, sign language interpreters, or primarily written information may facilitate communication and improve the perioperative environment for these patients [26].

\section{Learning points}

Waardenburg syndrome is a primary defect involving the division and migration of neural crest cells with involvement of melanocytes, facial and laryngeal cartilage, and the enteric autonomic nervous system. Phenotypic characteristics of Waardenburg syndrome include lack of pigmentation of the hair (white forelock), vibrant blue eyes or heterochromia due to lack of pigmentation of the iris or heterochromia, distinctive facial abnormalities (laterally displaced inner canthi and a wide nasal bridge), sensorineural hearing loss, and upper extremity malformations (Table 1). Waardenburg syndrome is 
a neural crest cell proliferation disorder caused by mutation in the PAX3, SOX10, MLF 23, ENDN or EDNRB, or ENF genes. Although anesthesia-related information regarding anesthesia and airway management in Waardenburg syndrome is limited, specific facial features and muscle contractures with limited neck mobility may cause difficulties with both direct laryngoscopy and endotracheal intubation. Neural crest cell mutations, particularly in the PAX3 gene, may also result in congenital heart disease, which should be assessed for prior to anesthetic care.

\section{Acknowledgments}

None to declare.

\section{Financial Disclosure}

None to declare.

\section{Conflict of Interest}

None to declare.

\section{Informed Consent}

Informed consent was obtained from a parent for anesthetic care and use of patient data for publication purposes. The patient information was de-identified for publication.

\section{Author Contributions}

MH performed the initial case review and manuscript preparation, literature review, and editing of subsequent revisions. JT contributed to decision making, literature review, and editing of the manuscript.

\section{Data Availability}

The data supporting the findings of this case report are available from the authors.

\section{References}

1. Read AP, Newton VE. Waardenburg syndrome. J Med Genet. 1997;34(8):656-665.

2. Waardenburg PJ. A new syndrome combining developmental anomalies of the eyelids, eyebrows and nose root with pigmentary defects of the iris and head hair and with congenital deafness. Am J Hum Genet. 1951;3(3):195253.

3. Klein D. Albinisme partiel (leucisme) avec surdi-mutite, blepharophimosis et dysplasie myo-osteo-articulaire. Helv Paediatr Acta. 1950;5:38-58.

4. Goodman RM, Lewithal I, Solomon A, Klein D. Upper limb involvement in the Klein-Waardenburg syndrome. Am J Med Genet. 1982;11(4):425-433.

5. Ambi US, Adarsh ES, Hatti R, Samalad V. Anesthetic management of Shah-Waardenburg syndrome: Experience of two cases and review of literature. Saudi J Anaesth. 2012;6(2):172-174.

6. Peker K, Ergil J, Ozturk I. Anaesthesia management in a patient with Waardenburg syndrome and review of the literature. Turk J Anaesthesiol Reanim. 2015;43(5):360362.

7. Bondurand N, Pingault V, Goerich DE, Lemort N, Sock $\mathrm{E}$, Le Caignec $\mathrm{C}$, Wegner $\mathrm{M}$, et al. Interaction among SOX10, PAX3 and MITF, three genes altered in Waardenburg syndrome. Hum Mol Genet. 2000;9(13):1907-1917.

8. Doubaj Y, Pingault V, Elalaoui SC, Ratbi I, Azouz M, Zerhouni H, Ettayebi F, et al. A novel mutation in the endothelin B receptor gene in a moroccan family with shahwaardenburg syndrome. Mol Syndromol. 2015;6(1):4449.

9. Watanabe A, Takeda K, Ploplis B, Tachibana M. Epistatic relationship between Waardenburg syndrome genes MITF and PAX3. Nat Genet. 1998;18(3):283-286.

10. Nataf V, Lecoin L, Eichmann A, Le Douarin NM. Endothelin-B receptor is expressed by neural crest cells in the avian embryo. Proc Natl Acad Sci U S A. 1996;93(18):9645-9650.

11. Michalek P, Hodgkinson P, Donaldson W. Fiberoptic intubation through an I-gel supraglottic airway in two patients with predicted difficult airway and intellectual disability. Anesth Analg. 2008;106(5):1501-1504.

12. Kfoury T, Staiti G, Baujard C, Benhamou D. Pudendal nerve block by nerve stimulation in a child with Waardenburg disease. Paediatr Anaesth. 2008;18(12):1267-1268.

13. Yanes-Vidal GJ, Garcia-Perla JL, Alarcon-Rubio M, Martinez-Canguelossi S. Apnoea episodes in Hirschsprung's disease and the anaesthesia implications of neurocristopathies. Paediatr Anaesth. 2004;14(3):280-281.

14. Kim SO. IV Deep sedation management of Waardenburg syndrome child during dental treatment: A case report. J Korean Dent Soc Anesthesiol. 2006;6:6-12.

15. Mizushima A, Nitami K, Kikuchi T, Kugimiya T, Ohya T, Miyano T. Anesthetic problems in a child with Waardenburg's syndrome and Hirschsprung's disease. J Anesth. 1996;10(2):144-146.

16. Sree Mounika GD, Murali Prabakar Y, Sharada M, Kondareddy R, Raghuram CG. Anaesthesia management in Waardenburg syndrome with Hirschsprung's Disease. Inter J Sci Res. 2020;9:1874-1875.

17. Kushikata T, Tonosaki M, Noguchi S, Matsumoto A, Sasaki A, Hirota K. Anasthetic management of cochlear implantation in an infant with Waardenburg syndrome. J Anesth. 2017;37:168-171.

18. Pekcan Y, Tuncali B, Sumer OY. Anesthesia management in a patient with Waardenburg syndrome. Turk J Anaesthesiol Reanim. 2020;28:131-134.

19. Engelhardt T, Weiss M. A child with a difficult air- 
way: what do I do next? Curr Opin Anaesthesiol. 2012;25(3):326-332.

20. Thapa R, Mallick D, Ghosh A, Ghosh A. Waardenburg syndrome associated with laryngomalacia. Singapore Med J. 2009;50(12):e401-403.

21. Banerjee AK. Waardenburg's syndrome associated with ostium secundum atrial septal defect. J R Soc Med. 1986;79(11):677-678.

22. Morgan SC, Lee HY, Relaix F, Sandell LL, Levorse JM, Loeken MR. Cardiac outflow tract septation failure in Pax3-deficient embryos is due to p53-dependent regulation of migrating cardiac neural crest. Mech Dev. 2008;125(9-10):757-767.
23. Raissi D, Christie A, Applegate K. Waardenburg syndrome and left persistent superior vena cava. J Clin Imaging Sci. 2018;8:44.

24. Mathieu M, Bourges E, Caron F, Piussan C. [Waardenburg's syndrome and severe cyanotic cardiopathy]. Arch Fr Pediatr. 1990;47(9):657-659.

25. Baspinar O, Gungor M, Parlak M, Coskun Y. Waardenburg syndrome type II and dilated cardiomyopathy in a child. Pediatr Int. 2006;48(1):100-102.

26. Chowdhry V, Padhi M, Mohanty BB, Biswal S. Perioperative challenges in management of a deaf and dumb patient posted for high-risk cardiac surgery. Ann Card Anaesth. 2016;19(3):564-567. 